\title{
Comparison between Precipitin and ELISA Tests in the Bloodmeal Detection of Aedes aegypti (Linnaeus) and Aedes fluviatilis (Lutz) Mosquitoes Experimentally Fed on Feline, Canine and Human Hosts
}

\author{
Luciana AM Gomes/ ${ }^{+}$, Rosemere Duarte*, Dinair C Lima**, \\ Beatriz Sanson Diniz*, Maria Lucia Serrão***, Norma Labarthe
}

\begin{abstract}
Faculdade de Veterinária, Centro de Ciências Médicas, Universidade Federal Fluminense, Rua Itaocara 88, 24240-100 Niterói, RJ, Brasil *Laboratório de Imunodiagnóstico, Departamento de Ciências Biológicas, Escola

Nacional de Saúde Pública-Fiocruz, Rio de Janeiro, RJ, Brasil **Laboratório de Transmissores de

Hematozoários, Departamento de Entomologia, Instituto Oswaldo Cruz-Fiocruz, Rio de Janeiro, RJ, Brasil

***Universidade Federal Rural do Rio de Janeiro, Seropédica, RJ, Brasil
\end{abstract}

The identification of arthropod bloodmeals is important in many epidemiological studies, as, the understanding of the life cycle of vectors and the patogens they transmit, as well as helping to define arthropods' control strategies. The precipitin test has been used for decades, but ELISA is slowly becoming more popular. To compare the two tests for sensitivity, specificity and accuracy to detect small insect bloodmeals, Aedes aegypti or Ae. fluviatilis mosquitoes were fed either on feline, canine or human hosts. Mosquitoes were frozen at 6, 12, 24, 48 or $72 \mathrm{~h}$ after feeding. Precipitin test showed better specificity and accuracy and ELISA test showed higher sensitivity. Better results with both tests were achieved when mosquitoes were frozen within $48 \mathrm{~h}$ from feeding.

Key words: bloodmeal identification - mosquito - ELISA - canine blood - feline blood - human blood

The determination of mosquitos' bloodmeal helps to understand pathogen life cycles, their potential hosts and to identify control strategies (Boreham 1975, Tempelis 1975, Ngumbi et al. 1992). Precipitin tests have been used to detect insects' bloodmeals for many decades (Bull \& King 1923 ) and since the 80's ELISA has been introduced as a better alternative (Burkot et al. 1981). Each test has its advantages and restrictions and should be choosen for better accuracy. The present study was conducted, in order to find a comparison in sensitivity, specificity or accuracy between the two tests for bloodmeal identification in mosquitoes.

The mosquitoes used in the present study were raised in laboratory and their species were either Aedes aegypti (Linnaeus) or Ae. fluviatilis (Lutz). Immunized rabbit serum with total proteins of fe-

\footnotetext{
${ }^{+}$Corresponding author. Fax: +55-21-714.9302. E-mail cmgomes@cruiser.com.br Received 12 September 2000 Accepted 28 March 2001
}

line, canine and human serum (Gill 1984) were used in both tests after being titered and absorbed to higher specificity (Weitz 1952, Duarte 1997). Ninety-five young mosquito females were fed once, for $60 \mathrm{~min}$, on dogs, cats or human volunteer (total of 285 mosquitoes). After feeding, mosquitoes were kept in groups of 19 and each group was frozen at $6,12,24,48$ or $72 \mathrm{~h}$ and kept at $-20^{\circ} \mathrm{C}$ until processing. Digestive contents were taken and diluted at 1:10 in PBS 0.01 M-pH 7.2 (Beier et al. 1988) to the precipitin test. Before the dilution, the color of each sample was observed subjectively, recorded, and unfed mosquitoes were sorted out. Negative controls were obtained using the above technique with unfed mosquitoes. Antiserum reached titers 1:30,000 (anti-feline and antihuman) and 1:16,000 (anti-canine). Results were recorded double-blind. ELISA tests were run with the same samples and antisera used for precipitin, although antisera were diluted at 1:5,000. Samples were diluted, in double, at 1:50 in carbonate bicarbonate buffer ( $\mathrm{pH}$ 9.6) and applied to 96 well polystyrene microplate (Alfesa, SP, Brasil). After incubation, plates were washed once in PBS 0,01 M added with tween 20 diluted $0.05 \%$ and dried. Diluted antiserum was than added to the wells and 
the microplate incubated at $37^{\circ} \mathrm{C}$ for $45 \mathrm{~min}$. After another wash, the conjugate was added, and after another incubation and wash, the substrate was applied. The plates were analyzed in microplate reader using $492 \mathrm{~nm}$ operational filter and $600 \mathrm{~nm}$ reference filter (Burkot et al. 1981). Cut off was established as the mean of negative control plus two standard deviations. Positive samples were those reading $10 \%$ over the cut off. Sensitivity, specificity and accuracy were stablished according to Rouquayrol (1994).

Approximately $80 \%$ of the colorless samples did not react, suggesting that those mosquitoes did not blood-feed enough to show any reaction and were therefore discarded. Both tests showed better sensitivity when mosquitoes were frozen less than $24 \mathrm{~h}$ after the bloodmeal. Precipitin test specificity was high when using anti-human or anti-canine serum with mosquito bloodmeals less than $24 \mathrm{~h}$ before freezing. However, the anti-feline serum was the least specific. The anti-feline antiserum system did not fall below $79 \%$ within $12 \mathrm{~h}$ (Table I). ELISA test results were always lower in specificity (Table I), and showed better sensitivity when compared to precipitin (Table II), and when accuracy is taken into consideration, precipitin showed to be a stronger test (Table III).

In an overall analysis, precipitin showed slightly better results, especially when specificity was the main requirement or when accuracy was taken into consideration. Perhaps in situations where sensitivity is to be highlighted, ELISA may be the choice. One must keep in mind that specificity and sensitivity were better when samples came from mosquitoes fed less than $48 \mathrm{~h}$ before digestion process was stoped by freezing, as stated (Bukort et al. 1981, Ngumbi et al. 1992, Savage et al. 1993). The system to detect canine blood in mosquitoes' gut was less sensitive than the system to detect feline blood, which can be explained by the differ-

\section{TABLE I}

Precipitin and ELISA tests specificity in identifying bloodmeal of laboratory raised Aedes aegypti or Ae. fluviatilis after feeding on a known host

\begin{tabular}{llrrrrr}
\hline & & \multicolumn{5}{c}{ Time after feeding (\%) } \\
\cline { 3 - 7 } Antisera & $6 \mathrm{~h}$ & $12 \mathrm{~h}$ & $24 \mathrm{~h}$ & $48 \mathrm{~h}$ & $72 \mathrm{~h}$ \\
\hline Feline & Precipitin & 96 & 79 & 88 & 77 & 100 \\
& ELISA & 88 & 83 & 73 & 82 & 56 \\
\multirow{5}{*}{ Canine } & Precipitin & 100 & 100 & 97 & 89 & 100 \\
& ELISA & 82 & 83 & 90 & 93 & 73 \\
Human & Precipitin & 100 & 100 & 100 & 100 & 100 \\
& ELISA & 94 & 96 & 78 & 64 & 100 \\
\hline
\end{tabular}

ence in the antiserum titers. In the present paper, the precipitin test showed to be more sensitive and specific than ELISA to detect mosquitoes' bloodmeal origin, besides being easy to perform and being a low cost technique.

\section{TABLE II}

Precipitin and ELISA tests sensitivity in identifying bloodmeal of laboratory raised Aedes aegypti or Ae. fluviatilis after feeding on a known host

\begin{tabular}{llrrrrr}
\hline & & \multicolumn{5}{c}{ Time after feeding (\%) } \\
\cline { 3 - 7 } Antisera & $6 \mathrm{~h}$ & $12 \mathrm{~h}$ & $24 \mathrm{~h}$ & $48 \mathrm{~h}$ & $72 \mathrm{~h}$ \\
\hline Feline & Precipitin & 100 & 88 & 81 & 7 & - \\
& ELISA & 100 & 54 & 56 & 7 & - \\
\multirow{5}{*}{ Canine } & Precipitin & 27 & 54 & 73 & - & - \\
& ELISA & 7 & 62 & 100 & 50 & - \\
Human & Precipitin & 83 & 64 & 27 & 14 & 38 \\
& ELISA & - & 64 & 73 & - & 25 \\
\hline
\end{tabular}

- : without reaction

\section{TABLE III}

Precipitin and ELISA tests accuracy in identifying bloodmeal of laboratory raised Aedes aegypti or Ae. fluviatilis after a feeding on a known host

\begin{tabular}{llrrrrr}
\hline & & \multicolumn{5}{c}{ Time after feeding (\%) } \\
\cline { 3 - 7 } Antisera & & $6 \mathrm{~h}$ & $12 \mathrm{~h}$ & $24 \mathrm{~h}$ & $48 \mathrm{~h}$ & $72 \mathrm{~h}$ \\
\hline \multirow{2}{*}{ Feline } & Precipitin & 98 & 83 & 86 & 50 & 75 \\
& ELISA & 93 & 73 & 67 & 53 & 42 \\
Canine & Precipitin & 76 & 85 & 90 & 69 & 92 \\
& ELISA & 56 & 76 & 93 & 83 & 67 \\
\multirow{4}{*}{ Human } & Precipitin & 96 & 90 & 74 & 67 & 58 \\
& ELISA & 72 & 86 & 76 & 39 & 50 \\
\hline
\end{tabular}

\section{REFERENCES}

Beier JC, Perkins PV, Wirtz RA, Koros J, Diggs D, Gargan TP, Koech DK 1988. Bloodmeal identification by direct enzyme-linked immunosorbent assay (ELISA), tested on Anopheles (Diptera: Culicidae) in Kenya. J Med Entomol 25: 9-16.

Boreham PFL 1975. Some application of bloomeal identifications in relation to the epidemiology of vectorborne tropical disease. Trans $R$ Soc Trop Med Hyg 78: 83-91.

Bull CG, King WV 1923. The identification of the bloodmeal of mosquitoes by means of the precipitin test. Am J Trop Med Hyg 3: 491-496.

Burkot TR, Goodman WG, Foliart GR 1981. Identification of mosquito blood meals by enzyme-linked immunosorbent assay. Am J Trop Med Hyg 30: 13361441.

Duarte R 1997. Ensaio Imunoenzimático (ELISA) para 
Identificação Experimental de Fontes Alimentares em Panstrongylus megitus (Burmeister, 1835) (Hemiptera: Reduviidae), MSc Thesis, Fundação Oswaldo Cruz, Rio de Janeiro, 88 pp.

Gill GS 1984. Production of antisera for the serological identification of blood meals of arthropods. Trans $R$ Soc Trop Med Hyg 78: 233-234.

Ngumbi PM, Lawyer PG, Johson RN, Kilu G, Asiago C 1992. Identification by phlebotominae sandflies bloodmeals from Baringo district, Kenya, by direct enzyme-lynked immunosorbent assay (ELISA). Med Vet Entomol 6: 385-388.
Rouquayrol MZ 1994. Epidemiologia \& Saúde, 4th ed., Médica e Científica Ltda, São Paulo, 200 pp.

Savage HM, Niebylski ML, Smith GC, Mitchell CJ, Craig GB 1993. Host feeding patterns of Aedes albopictus (Diptera: Culicidae) at a temperate North american site. J Med Entomol 30: 27-34.

Tempelis CH 1975. Host-feeding patterns of mosquitoes, with a review of advances in analysis of blood meals by serology. J Med Entomol 11: 635-653.

Weitz B 1952. The antigenicity of sera of man and animals in relation to the preparation of specific precipitating antisera. J Hygiene 50: 275-294. 
696 Bloodmeal Detection of Mosquitoes - Luciana AM Gomes et al. 